\title{
O desafio da saúde pública no contexto do suicídio indígena: uma revisão integrativa
}

\author{
The challenge of public health in the context of indigenous suicide: an integrative review
}

El desafío de la salud pública en el contexto del suicidio indígena: una revisión integradora

Laris Lucianny dos Santos de Araújo ${ }^{1 *}$, Elaine Cristina Silvano Soares ${ }^{1}$, Eurides Souza de Lima ${ }^{1}$, Paula Figliuolo da Cruz Borges ${ }^{1}$.

\section{RESUMO}

Objetivo: Descrever os motivos que leva o indígena a cometer suicídio no contexto da Saúde Pública. Métodos: Trata-se de uma pesquisa descritiva, exploratória, qualitativa do tipo revisão integrativa da literatura, onde foram utilizados artigos científicos de 2017 a 2021, encontrados nas bases SCIELO, BIREME e LILACS. Resultados: Selecionou-se 11 artigos dos quais emergiram 3 categorias: Determinantes que levam os indígenas a cometerem suicídio; Meios de combater o suicídio na população indígena; O suicídio e a crença indígena. Essas categorias mostram a importância de entender e respeitar o conhecimento e crença dos povos indígenas, para o melhor planejamento de medidas que visem reduzir o autocídio sem impor mudanças na cultura indígena. Considerações finais: O suicídio do povo indígena, assim como em qualquer outra cultura e sociedade, atinge pessoas de todas as idades e muitas são as causas, no entanto, entre as principais causas está a dominação do homem branco, que desde muito tempo consegue levar destruição a esse grupo, por meio da morte cultural ocasionada pelas mudanças no estilo de vida do povo indígena.

Palavras chave: Suicídio, Indígena, Tentativa de suicídio, Saúde mental.

\begin{abstract}
Objective: To describe the reasons that lead indigenous people to commit suicide in the context of Public Health. Methods: This is a descriptive, exploratory, qualitative research of the integrative literature review type, which used scientific articles from 2017 to 2021, found in the SCIELO, BIREME and LILACS databases. Results: 11 articles were selected from which 3 categories emerged: Determinants that lead indigenous people to commit suicide; Means of combating suicide in the indigenous population; Suicide and indigenous belief. These categories show the importance of understanding and respecting the knowledge and beliefs of indigenous peoples, in order to better plan measures aimed at reducing autocide without imposing changes in indigenous culture. Final considerations: The suicide of indigenous people, as in any other culture and society, affects people of all ages and there are many causes, however, among the main causes is the domination of the white man, who has been able to lead for a long time. destruction to this group, through cultural death caused by changes in the lifestyle of the indigenous people.
\end{abstract}

Keywords: Suicide, Indigenous, Attempted suicide, Mental health.

\section{RESUMEN}

Objetivo: Describir las razones que llevan a los indígenas al suicidio en el contexto de la Salud Pública. Métodos: Se trata de una investigación descriptiva, exploratoria, cualitativa de tipo revisión integradora de literatura, que utilizó artículos científicos de 2017 a 2021, encontrados en las bases de datos SCIELO, BIREME y LILACS. Resultados: Se seleccionaron 11 artículos de los cuales surgieron 3 categorías: Determinantes que llevan a los indígenas al suicidio; Medios para combatir el suicidio en la población indígena; Suicidio y creencias indígenas. Estas categorías muestran la importancia de comprender y respetar los

${ }^{1}$ Centro Universitário Faculdade Metropolitana de Manaus (CEUNI-FAMETRO), Manaus - AM.

*E-mail: larislucianny100@gmail.com 
conocimientos y creencias de los pueblos indígenas, a fin de planificar mejor las medidas encaminadas a reducir el autocidio sin imponer cambios en la cultura indígena. Consideraciones finales: El suicidio de los indígenas, como en cualquier otra cultura y sociedad, afecta a personas de todas las edades y son muchas las causas, sin embargo, entre las principales se encuentra la dominación del hombre blanco, quien ha sabido liderar por un Desde hace mucho tiempo la destrucción de este grupo, a través de la muerte cultural provocada por cambios en el estilo de vida de los pueblos indígenas.

Palabras clave: Suicidio, Indígena, Intento de suicidio, Salud mental.

\section{INTRODUÇÃO}

O suicídio é um ato consciente, violento e agressivo contra si próprio cometido por pessoas que se encontram vulneráveis e possuem a intenção de pôr fim a própria vida. Quem comete o suicídio, acredita ser este o único meio de solucionar suas dores emocionais e psicológicas, uma fuga definitiva de seus problemas. O suicídio é tratado, desde o século XVIII, como um fenômeno social, sociológico, econômico e filosófico de acordo com o ponto de vista histórico, estando atualmente na $10^{\text {a }}$ Classificação Internacional de Doenças (CID) e reconhecido como causa externa (RIBEIRO NM, et al., 2018; RIBEIRO JM e MOREIRA MR, 2018).

Apesar do conceito de suicídio em interromper a própria vida, a realidade é que o suicida não quer morrer, mas sim pôr fim aos seus problemas e conflitos, vivenciando a ilusão de solução e não de morte. Até chegar à consumação do ato, o indivíduo vive uma série de situações que interagem entre si e servem de gatilho para o início de uma crise suicida. O momento em que se inicia o comportamento suicida, é quando o sujeito inicia a autoagressão e passa por ideação e desejos de morrer, tentativa e o autocídio, sendo considerado como tentativa de suicídio o ato falho do autoextermínio (ALCÂNTARA MÜLLER S, 2017).

Sobre as taxas de suicídio, o Ministério da Mulher, da Família e dos Direitos Humanos (MDH) afirma que são mais altas em países capitalistas avançados e de nível socioeducacional médio e baixo, sendo os homens quem mais chegam a cometer suicídio na fase adulta, e as mulheres geralmente cometem entre 15 e 19 anos, o Brasil está em oitavo lugar entre os países latinos que possuem maior índice de suicídio, e em 29 lugar entre os países em que os casos mais crescem, estando a região Norte em primeiro lugar com $77 \%$ de crescimento (MDH, 2019).

Segundo Souza MLP e Onety Júnior RTS (2017), os indígenas apesar de representarem apenas 0,4\% da população brasileira, possuem índices de suicídio 2,3 vezes maior que entre os não indígenas. De 2006 a 2010, a taxa de suicídio foi estimada em 12,6/100 mil habitantes, sendo o Amazonas, Mato Grosso do Sul e Roraima os estados com maior sobremortalidade, com predomínio de autocídio entre os homens de 24 anos de idade, por meio do enforcamento e dentro da própria residência. No entanto houve casos de crianças de 12 anos, e a idade máxima dos indivíduos que cometeram a autodestruição foi de 41 anos.

Consta que a cada 40 segundos morre uma pessoa por suicídio no mundo, colocando o suicídio entre as 20 maiores causas de óbitos em todas as idades, chegando a 1 milhão de mortes por ano. Dado o exposto, considera-se tal ato um importante problema de saúde pública, necessitando de políticas públicas que tenham por objetivo prevenir não só o ato suicida, mas também as consequências acarretadas. As tentativas previas podem chegar a dez vezes mais que o próprio suicídio. Em questão de fatores de risco aponta-se as tentativas, o isolamento social, pensamentos de morte, declaração de querer morrer, história familiar de doenças mentais, agressão ou abuso e fatores biológicos e socioeconômicos (PEREIRA AS, et al., 2018; D'EÇA JÚNIOR A, et al., 2019).

Foi divulgado em agosto de 2006 as Diretrizes Brasileiras para um Plano Nacional de Prevenção do Suicídio, com objetivo de prevenir condutas suicidas, por meio de ações como capacitação de profissionais para o atendimento do sujeito que atentou contra sua vida. As políticas públicas por meio de programas de prevenção podem ocorrer de muitas formas, como a campanha do Setembro Amarelo que alerta toda a sociedade para que saibam identificar um sujeito em crise, e o próprio indivíduo e a família para que saibam que existe meios de conseguir ajuda e apoio, pois o suicídio causa sentimentos negativos não só em quem tenta o ato, mas também nas pessoas que convivem com o suicida (MENEZES JG, et al., 2021). 
No mundo inteiro, os indígenas enfrentam problemas e dificuldades, eles vivem menos que os não indígenas, apesar das melhorias, ainda hoje os serviços de saúde e educação são inferiores aos oferecidos para o restante da população, e os índices de desemprego também são mais altos, além disso, algumas situações como ameaças aos seus saberes, crenças, costumes e territórios os tornam frágeis e vulneráveis a problemas mais graves como o grande aumento nos casos de tabagismo, alcoolismo, encarceramento, uso abusivo de drogas, depressão e o suicídio entre os adolescentes e jovens adultos (VICTAL VJRC, et al., 2019).

A Funasa alerta o Brasil a respeito da depressão e do suicídio, que estão cada vez mais presentes entre os adolescentes e jovens adultos indígenas de diversas comunidades, estando o suicídio relacionado tanto a fatores sociais quanto culturais, sendo que cada grupo indígena possui sua própria compreensão sobre o autocídio, além do mais, este fenômeno afeta mundialmente até mesmo os nativos de países desenvolvidos, mostrando a necessidade de políticas públicas voltadas a essa população com foco no suicídio (SOUZA RSB, et al., 2020).

De acordo com Victal VJRC, et al. (2019), por muito tempo os indígenas eram negligenciados nos censos demográficos, tornando incerto a idoneidade dos dados, porém, a partir de 2010 o Censo finalmente realizou investigações e levantamentos de dados exatos nas comunidades indígenas, trazendo dados confiáveis, deixando saber que, os índices de suicídio nos povos indígenas no Amazonas chegou a 18,4/100.000 de 2006-2010, entre os óbitos 37,7/100.000 eram adolescentes e jovens adultos de 15-24 anos de idade, no Centro-Oeste, houve 410 suicídios no Mato Grosso do Sul entre 2000 a 2008, 65\% dos casos eram entre os de 15-29 anos, e a maioria eram homens.

O relatório do Conselho Indigenista Missionário (CIMI) aponta que comparado ao ano de 2016, houve aumento de $20 \%$ dos casos de suicídio entre os indígenas no ano de 2017 , e de acordo com o Ministério da Saúde, o número de suicídios nos povos indígenas foi três vezes maior que a média nacional, sendo a média nacional de 5,7 óbitos para 100 mil habitantes, entre as mortes indígenas por autocídio cerca de $44,8 \%$ foram de crianças e adolescentes em torno de 10 a 19 anos de idade, bem diferente ao panorama nacional de que são adolescentes e jovens adultos o maior índice de afetados pelo autoextermínio (MARTINS F, 2021).

Portanto, o objetivo deste estudo foi descrever os motivos que levam o indígena a cometer suicídio no contexto da Saúde Pública.

\section{MÉTODOS}

Trata-se de uma pesquisa descritiva exploratória qualitativa do tipo Revisão Integrativa da Literatura (RIL), sendo está metodologia fundamentada em conhecimento cientifico, partindo de uma questão problema, sendo realizado uma pesquisa, em seguida avaliação de todo o material encontrado, e análise dos dados e os resultados obtidos (SOUSA LMM, et al., 2017).

O levantamento das informações foi coletado nas bibliotecas virtuais seguintes: Literatura Latina Americana e do Caribe (LILACS), Biblioteca Virtual em Saúde (BVS), Scientific Electronic Library (SCIELO), usando os seguintes descritores: "Suicídio", "Indígena", "Tentativa de Suicídio", "Saúde Mental".

Foram usados como critérios de inclusão: artigos disponíveis na íntegra e on-line, publicados nos referidos bancos de dados nos últimos cinco anos de 2016 a 2021, disponíveis para download e escritos em língua portuguesa, inglesa e espanhol que retratem a temática dos resumos pertinentes aos objetivos (Figura 1).

Usados como critérios de exclusão foram: duplicatas, livros, mídias, reportagens, monografias, teses e dissertações, artigos não disponíveis para download, além de resumos com conteúdo fora da temática, artigos que não respondam as questões de pesquisa e que forem de outros idiomas (Figura 1).

A posteriori, houve uma análise do material encontrado, organizado e separado de acordo com as seguintes etapas: armazenamento dos artigos encontrados conforme as bases de dados; armazenamento dos artigos encontrados dentro dos critérios de inclusão; organização dos artigos, conforme características teórico-metodológicas. 
Figura 1 - Fluxograma dos critérios de inclusão e exclusão da pesquisa.

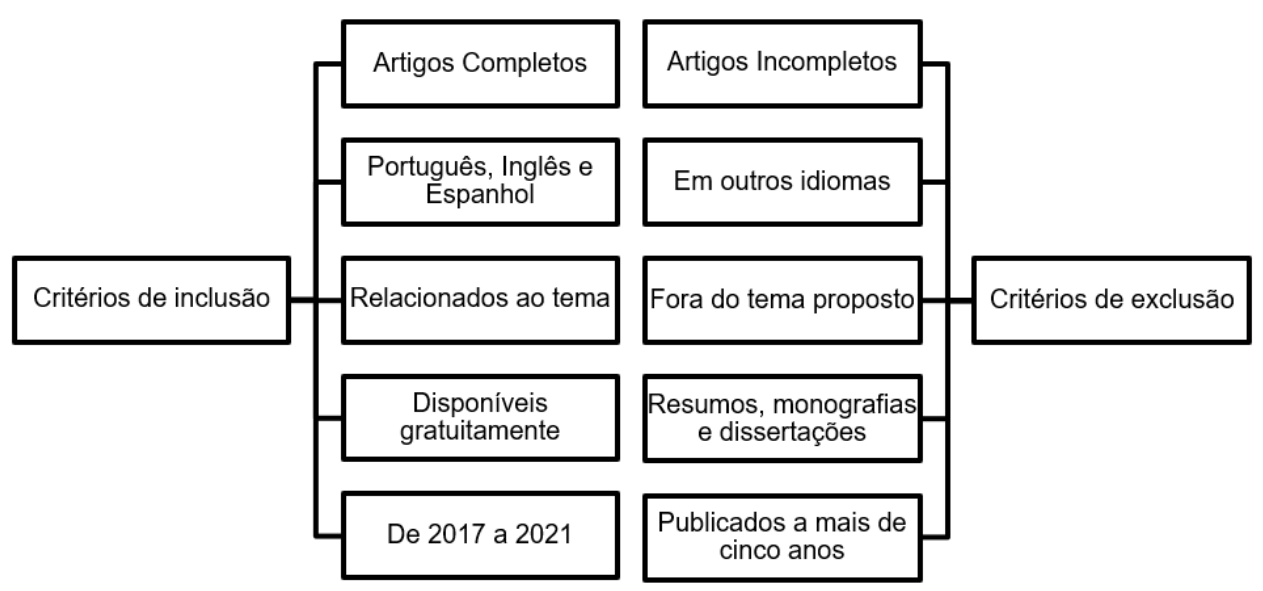

Fonte: Araújo LLS, et al., 2021.

\section{RESULTADOS E DISCUSSÃO}

Foram encontrados 45 artigos na primeira etapa da pesquisa, que foram organizados e analisados conforme os critérios de inclusão e exclusão, em seguida, foram excluídos 5 duplicatas encontradas, restando 40 artigos. Após a leitura parcial desses artigos, houve a exclusão de 5 artigos por serem monografias e dissertação. Na segunda etapa, os artigos foram lidos na íntegra, sendo excluídos 24 artigos que não responderam as questões de pesquisa. Diante disto, para compor este estudo, foram selecionados 11 artigos entre os anos de 2016 a 2021, sendo 3 em português da LILACS, 2 em português da BVS, 2 em português da SCIELO, 1 em inglês e 3 em espanhol também da SCIELO (Figura 2).

Em seguida, a discussão foi organizada com as seguintes categorias temáticas: a) Determinantes que levam os indígenas a cometerem suicídio; b) Meios de combater o suicídio na população indígena; c) $O$ suicídio e a crença indígena.

Figura 2 - Fluxograma de busca e seleção dos artigos.

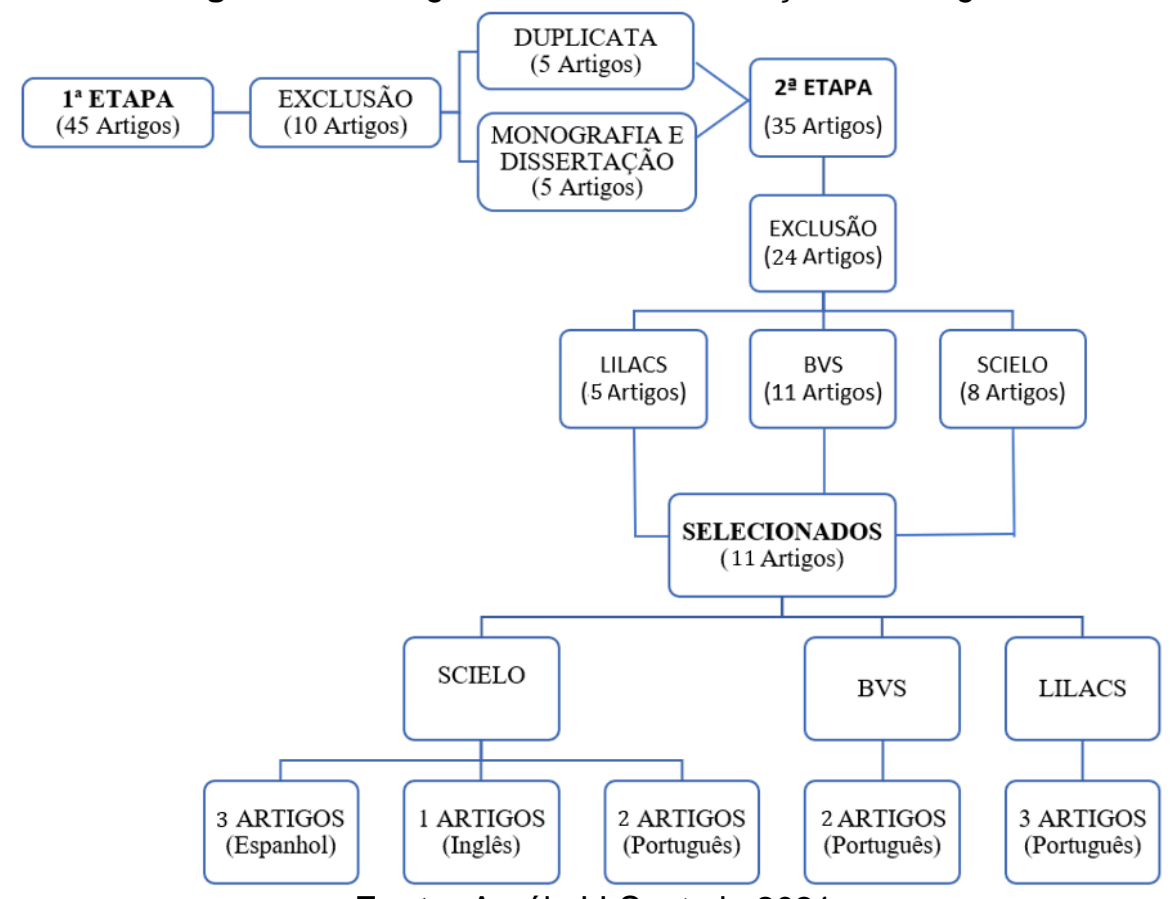

Fonte: Araújo LLS, et al., 2021.

Os artigos selecionados para a elaboração deste estudo e desenvolvimento das categorias, foram organizados e estão descritos no Quadro 1. 
Quadro 1 - Descrição dos artigos selecionados.

\begin{tabular}{|c|c|c|c|c|c|}
\hline Título & Idioma & Autores/ Ano & Base & Delineamento & Conclusão \\
\hline $\begin{array}{l}\text { Análisis psicosocial del suicidio en } \\
\text { personas jóvenes }\end{array}$ & Espanhol & $\begin{array}{l}\text { Arroyo Araya } \mathrm{H} \mathrm{e} \\
\text { Herrera Gonzalez } \\
\text { DG (2019) }\end{array}$ & SCIELO & $\begin{array}{l}\text { Pesquisa de ação } \\
\text { participativa }\end{array}$ & $\begin{array}{l}\text { O ato suicida é uma forma de expressar um trauma psicossocial } \\
\text { desenvolvida por uma série de fatores que afetam negativamente as } \\
\text { identidades culturais, sendo o vínculo e fortalecimento da cultura ajudam } \\
\text { no enfrentamento do suicídio indígena }\end{array}$ \\
\hline $\begin{array}{l}\text { Conducta suicida en pueblos indígenas: } \\
\text { una revisión del estado del arte }\end{array}$ & Espanhol & $\begin{array}{l}\text { Vargas-Espindola } \\
\text { A, et al. (2017) }\end{array}$ & SCIELO & $\begin{array}{l}\text { Revisão integrativa } \\
\text { da literatura }\end{array}$ & $\begin{array}{l}\text { Alguns desencadeantes para o suicídio indígena é o abuso de álcool e } \\
\text { drogas, depressão, ansiedade e transtornos afetivos, entre outros. } \\
\text { Esses fatores podem apresentar-se associados com outros fatores. }\end{array}$ \\
\hline $\begin{array}{l}\text { Narrativas sobre la conducta suicida en } \\
\text { pueblos indígenas colombianos, 1993- } \\
2013\end{array}$ & Espanhol & $\begin{array}{l}\text { Urrego-Mendoza } \\
\text { ZC, et al. (2017) }\end{array}$ & SCIELO & $\begin{array}{l}\text { Pesquisa narrativa } \\
\text { qualitativa }\end{array}$ & $\begin{array}{l}\text { Para os povos indígenas Cubeo e Tucano, o que leva o povo ao suicídio } \\
\text { são os feitiços, enquanto outros grupos acreditam que cometer suicídio } \\
\text { leva a alma a vagar, e por isso, aqueles que apresentam comportamento } \\
\text { suicida são castigados. }\end{array}$ \\
\hline $\begin{array}{l}\text { Suicide in the Indigenous Population of } \\
\text { Latin America: A Systematic Review }\end{array}$ & Inglês & $\begin{array}{l}\text { Azuero AJ et al. } \\
\qquad(2017)\end{array}$ & SCIELO & $\begin{array}{l}\text { Revisão } \\
\text { Sistemática }\end{array}$ & $\begin{array}{l}\text { Deve-se considerar as crenças e cultura dos povos indígenas para que } \\
\text { se evite drásticas mudanças no estilo de vida desse grupo, pois essas } \\
\text { mudanças geram morte "cultural" e consequentemente leva o indígena } \\
\text { a cometer suicídio. }\end{array}$ \\
\hline $\begin{array}{l}\text { Onde e Como se Suicidam os Guarani e } \\
\text { Kaiowá em Mato Grosso do Sul: } \\
\text { Confinamento, Jejuvy e Tekoha }\end{array}$ & Português & $\begin{array}{l}\text { Staliano } \mathrm{P} \text {, et al. } \\
(2019)\end{array}$ & SCIELO & $\begin{array}{l}\text { Pesquisa qualitativa } \\
\text { de análise } \\
\text { documental }\end{array}$ & $\begin{array}{l}\text { A maioria dos indígenas que cometem o autocídio tem como motivo a } \\
\text { restrição territorial, perder suas terras gera conflitos e grande sofrimento, } \\
\text { pois para eles, a terra em que vivem possui valor emocional e cultural. }\end{array}$ \\
\hline $\begin{array}{l}\text { Narrativas indígenas sobre suicídio no } \\
\text { Alto Rio Negro, Brasil: tecendo sentidos }\end{array}$ & Português & $\begin{array}{l}\text { Souza MLP } \\
(2016)\end{array}$ & SCIELO & Pesquisa narrativa & $\begin{array}{l}\text { Além dos vários tipos de violência que os indígenas sofrem, muitas } \\
\text { vezes eles também perdem suas terras, necessitando da ajuda daqueles } \\
\text { que entendam o valor de suas terras e cultura. }\end{array}$ \\
\hline $\begin{array}{l}\text { Importância do atendimento qualificado } \\
\text { a indígenas com tentativa de suicídio: } \\
\text { relato de experiência }\end{array}$ & Português & $\begin{array}{l}\text { Almeida MN, et al. } \\
\qquad(2020)\end{array}$ & BVS & $\begin{array}{l}\text { Pesquisa qualitativa } \\
\text { do tipo descritiva }\end{array}$ & $\begin{array}{l}\text { A junção dos cuidados tradicionais e governamentais pode acontecer ao } \\
\text { envolver o líder da comunidade nas políticas públicas, pois eles são } \\
\text { importantes representantes que em muitos casos é o único com poder } \\
\text { restaurar o equilíbrio. }\end{array}$ \\
\hline $\begin{array}{l}\text { Mortalidade por suicídio entre crianças } \\
\text { indígenas no Brasil }\end{array}$ & Português & $\begin{array}{l}\text { Souza MLP } \\
(2019)\end{array}$ & LILACS & Estudo descritivo & $\begin{array}{l}\text { Fatores como abuso e violência doméstica levam crianças indígenas a } \\
\text { cometerem autocídio, pois apesar da pouca idade já carregam o peso } \\
\text { de uma vida conflituosa e cheia de dor. }\end{array}$ \\
\hline $\begin{array}{l}\text { Nas fronteiras dos impactos } \\
\text { expansionistas do capital sobre a saúde } \\
\text { dos povos indígenas no brasil: questões } \\
\text { para a compreensão do suicídio }\end{array}$ & Português & $\begin{array}{l}\text { Adsuara } \mathrm{CHC} \text {, et } \\
\text { al. (2019) }\end{array}$ & LILACS & $\begin{array}{l}\text { Revisão de } \\
\text { literatura }\end{array}$ & $\begin{array}{l}\text { Na maioria dos casos de suicídio indígena, os brancos são apontados } \\
\text { como culpados, e a prova disso é uma carta deixada pelos Guarani } \\
\text { Kaiowá de tekoha Pyelito kue/Mbarakay, onde eles questionam a quem } \\
\text { e qual justiça devem denunciar as violências sofrida e causada pela } \\
\text { própria Justiça Federal. }\end{array}$ \\
\hline $\begin{array}{l}\text { Suicídio na população indígena e não } \\
\text { indígena: uma contribuição para a } \\
\text { gestão em saúde }\end{array}$ & Português & $\begin{array}{c}\text { Braga CMR, et al. } \\
\qquad(2020)\end{array}$ & LILACS & $\begin{array}{l}\text { Estudo } \\
\text { epidemiológico, } \\
\text { descritivo, }\end{array}$ & $\begin{array}{l}\text { Os índios buscam no suicídio um escape para suas dores emocionais, é é } \\
\text { uma fuga da sua realidade, além disso, acreditam que após a morte } \\
\text { viverão uma vida bem melhor. }\end{array}$ \\
\hline
\end{tabular}




\section{Determinantes que levam os indígenas a cometerem suicídio}

O suicídio é um fenômeno de muitas causas, resultante da interação biológica, psicológica, genética, sociológica, ambiental e cultural, onde o homem busca por meio deste ato expressar sua insatisfação e frustração com a sua própria vida, pois vive em um ambiente que faz parte de si próprio e que não é possível superar, pois apesar de ser um ser social, também é considerado um produto da sua sociedade devido todas essas interações, causando neste indivíduo sentimentos negativos que o leva ao desejo de morte (ARROYO ARAYA H E HERRERA GONZALEZ DG, 2019).

As causas de suicídio entre os povos indígenas variam de acordo com a cosmologia de cada grupo, entretanto, para a maioria dos indígenas, a causa é a restrição territorial, pois o território tradicional possui grande importância para a saúde e a cultura desse grupo. O fato de muitos desses grupos serem despejados de suas terras por fazendeiros, políticos, comerciantes, empresas e usinas, leva os indígenas a uma relação conflituosa e consequentemente a luta pelo reconhecimento de seu território, que para eles, é mais que um espaço para plantar e colher, é uma relação cultural com a natureza, onde foi formado e organizado famílias e religiosidades (STALIANO P, et al., 2019).

Adsuara $\mathrm{CHC}$, et al. (2019) afirmam que, os brancos induzem os indígenas a cometerem suicídio, pois um dos maiores motivos pelo qual esse grupo comete o ato suicida é o processo de esbulhos que vivenciam desde muitos séculos atrás, com a chegada das primeiras caravelas no Brasil, onde o capitalismo revela-se historicamente como destruidor ambiental, social e cultural desses povos, podendo o suicídio ser efeito do processo colonial que ainda hoje é implementado.

Uma carta dos Guarani Kaiowá de Tekoha Pyelito kue/Mbarakay para o governo e justiça brasileira, também foi citada por Adsuara CHC, et al. (2019), deixando claro que o suicídio é uma manifestação dos impactos causados pela dominação do homem branco na forma de viver dos indígenas. A carta questiona a quem os Guarani podem denunciar as violências vivenciadas, já que a própria justiça contribui para essa violência, eles também falam que sabem que morrerão em pouco tempo independentemente de onde forem, sendo assim, pedem ao Governo e a Justiça Federal que decretassem a morte coletiva dos Guaranis, pois preferiam morrer e serem enterrados junto dos seus antepassados, no lugar onde viveram toda a vida.

O suicídio de indígenas deve ser discutido considerando a cultura e as crenças de cada grupo, sendo assim, Azuero AJ, et al. (2017) afirmam que ao passar por mudanças no estilo vida a população indígena sofre "morte cultural", devido a degradação ambiental e a influência da indústria. A industrialização aumentou os maus-tratos e o consumo de álcool, que associado a outros gatilhos como a pobreza, discriminação e perda da cultura, aciona o autoextermínio como rota de fuga da raiva, angústia e do medo, pois a rápida morte cultural que vivenciam causa forte sofrimento e desespero na população indígena.

O uso de bebida alcoólica, maconha e fumo são apontados por Vargas-Espindola A, et al. (2017) como a principal causa de suicídio entre os jovens indígenas que apresentam sentimentos de desesperança, já a violência física e sexual é gatilho para o suicídio entre as mulheres indígenas, que muitas vezes precisam conviver com seu agressor dentro da comunidade em que residem. Doenças como depressão, ansiedade, transtornos afetivos e estresse pós-traumático, principalmente associado a outros fatores também são causas que levam o indígena a cometer suicídio. Os adolescentes indígenas que presenciam ou vivem em conflito com os pais, também cometem autodestruição, principalmente pela pressão de uma vida precária.

Afirma que, o suicídio é um problema tão grave de saúde pública que afeta até mesmo as crianças indígenas, destacando como causas para esse evento: ter um familiar que consumou o autoextermínio, conflitos familiares, abuso infantil, uso de álcool e drogas pelos familiares, bullying e outros problemas na escola, e violência doméstica. Enfrentar uma vida tão complicada, sem oportunidades e conflituosa é cansativo para a criança, que acaba buscando descanso e paz na morte, acreditando ser essa a solução para tanta dor emocional, e muitas vezes dores físicas (SOUZA MLP, 2019).

\section{Meios de combater o suicídio na população indígena}

Muitos povos nativos perderam suas terras, tiveram sua cultura transformada e seu conhecimento menosprezado, e ainda hoje sofrem diversos tipos de violência. Diante de tanta dor, os indígenas necessitam 
de suporte e meios que busquem compreender o impacto desses acontecimentos em seu universo simbólico, assim como entender o que o suicídio representa em sua cultura, para que então possa ser criado estratégias coletivas menos etnocêntricas que combata o autocídio no meio deste grupo (SOUZA MLP, 2016).

Uma forma de combater o suicídio e proteger os indígenas deste mal é oferecer apoio social e familiar, além disso, Azuero AJ, et al. (2017) também afirma que programas voltados a escutar idosos e realizar atividades da cultura indígena são mais eficazes do que os programas baseados apenas nas comunidades. Porém, é necessário e importante inserir serviços médicos e psicológico nessas comunidades, com profissionais que reconheçam e respeitem a história, tradições e cultura desse povo, tentando interferir o mínimo possível em seu modo de vida.

É muito importante a atenção diferenciada a população indígena, sendo necessário a capacitação dos profissionais para que possam compreender o modo de viver de cada grupo e identificar os atos que precisam de atenção, reconhecendo e aceitando os saberes indígenas, considerando sua cultura, especificidade e práticas de saúde tradicionais. Oferecer e permitir lugar de fala para os jovens indígenas permite que seja criado vínculo entre eles e o profissional, através da fala e da escuta pode ser expresso medos e desejos, promovendo um espaço de cura, com diferentes pontos de vista, mas que ressignifica a vida de cada um (ALMEIDA MN, et al., 2020).

De acordo com o estudo de Silva DL, et al. (2019), oficinas de teatro e ações coletivas promove encontro e diálogo a respeito de problemas cotidianos que ocorrem dentro da comunidade. Uma ação realizada na aldeia Barreirinha do povo indígena Amanayé, no Estado do Pará, usou o teatro como instrumento de luta contra opressão e transformação da realidade, construindo três cenas com temas sobre overdose de drogas, violência contra a mulher e crianças após consumo de álcool, e violência sexual contra criança. Após as oficinas os fatores que levam ao suicídio foram reduzidos, tornando-se um caminho para ações preventivas de autocídio, levando os indígenas a reflexão e protagonismo diante de problemas cotidianos.

Incluir o xamã ou pajé em ações de políticas públicas voltadas a saúde indígena pode garantir que haja uma relação entre o cuidado tradicional e o governamental, pois para os povos originários, a causa da doença e do sofrimento mental muitas vezes é distorcida e associada a um agente externo. Quando se trata de suicídio, este agente na maioria das vezes é a feitiçaria, e somente o xamã pode restituir o equilíbrio por meio de seu conhecimento e da medicina tradicional (ALMEIDA MN, et al., 2020).

\section{O suicídio e a crença indígena}

Alguns grupos indígenas como os Sorowaha, acreditam que morrer enquanto é jovem, forte e de boa aparência garante uma passagem indolor para a vida após a morte, e por isso praticam rituais para a passagem adulta, onde os jovens fazem uso de substâncias psicotrópicas que causam convulsões e hipotensão. Entre essas substâncias está o konaha, e seu uso também serve para fortalecer os que conseguem sobreviver aos problemas que surgem. Outros povos indígenas acreditam que o suicídio é a verdadeira causa do surgimento de epidemias, pois os jovens que se suicidam passam a assombrar outros jovens (AZUERO AJ, et al., 2017).

Na visão do povo Guarani, ao nascer, dois pássaros sagrados passam a proteger o indígena, o Mokoy e Gwyra, eles guardam a força e a vontade de viver, garantindo uma boa e tranquila vida, após a morte, os pássaros voltam ao Cosmos. No entanto, Staliano $\mathrm{P}$, et al. (2019) relatam que alguns acontecimentos e sentimentos negativos podem espantar os pássaros, e sem eles, o indivíduo passa a fazer o que antes não faria, como o suicídio. Subjacente ao suicídio está o Jejuvy, que é o ato de enforcar-se, e ocorre devido um espírito maligno chamado Angué se instalar na garganta e despertar o desejo de cometer Jejuvi.

Alguns povos indígenas colombianos como Cubeo e Tucano, acreditam que o autocídio está associado a maldiçoes e feitiços, já para o povo Embera del Chocó, apresentar comportamento suicida quando se está em guerra significa que há desarmonia espiritual. Os povos Wiwa acreditam que quem comete suicídio leva consigo feitiços para o plano espiritual, e por isso sua alma passa a vagar para sempre, e aqueles que apresentam comportamentos suicidas recebem punições como: carregar pesadas pedras por horas nos braços, ficar de joelhos em cima de pedras, bens confiscados, exposição do corpo nu e exílio (URREGOMENDOZA ZC, et al., 2017). 
Para Braga CMR, et al. (2020), assim como para os "brancos", o suicídio pode ser para o indígena, um meio de se livrar de dores emocionais, conflitos e outros sofrimentos vivenciados, e de modo geral, a cosmologia indígena explica que a vida é apenas um momento que antecede a verdadeira vida, e a morte é o meio que a alma encontra para deixar o corpo e enfim passar a habitar em um lugar melhor, sem conflitos e dores.

\section{CONSIDERAÇÕES FINAIS}

O suicídio do povo indígena, assim como em qualquer outra cultura e sociedade, atinge pessoas de todas as idades e muitas são as causas, no entanto, entre as principais causas está a dominação do homem branco, que desde muito tempo consegue levar destruição a esse grupo, por meio da morte cultural ocasionada pelas mudanças no estilo de vida do povo indígena. O estudo traz grandes contribuições para enfermeiro no contexto da prevenção do suicídio nas populações indígenas, pois mostra que ações educativas e a capacitação dos profissionais de saúde são tecnologias leves que ajudam identificar precocemente os sinais de suicídio, bem como, o investimento das Políticas Públicas de Saúde voltados para Saúde mental nas comunidades indígenas, tendo em vista, que essa população necessita de cuidados específicos devido seus hábitos, costumes e crenças que são bem peculiares de cada etnia.

\section{REFERÊNCIAS}

1. ADSUARA CHC, et al. Nas fronteiras dos impactos expansionistas do capital sobre a saúde dos povos indígenas no brasil: questões para a compreensão do suicídio. Saúde Redes, 2019; 325-338.

2. ALCÂNTARA MÜLLER S, et al. Estratégias de prevenção e pósvenção do suicídio: Estudo com profissionais de um Centro de Atenção Psicossocial. Revista de Psicologia da IMED, 2017; 9(2): 6-23.

3. ALMEIDA MN, et al. Importância do atendimento qualificado a indígenas com tentativa de suicidio: relato de experiência. Revista do NUFEN, 2020; 12(3): 217-231.

4. ARROYO ARAYA H, HERRERA GONZALEZ DG. Análisis psicosocial del suicidio en personas jóvenes indígenas Bribris. Reflexiones, 2019; 98(2): 7-22.

5. AZUERO AJ, et al. Suicídio na População Indígena da América Latina: Uma Revisão Sistemática. rev.colomb.psiquiatr., 2017; 46(4): 237-242.

6. BRAGA CMR, et al. Suicide in indigenous and non-indigenous population: a contribution to health management. Rev Bras Enferm. 2020;73(1): e20200186.

7. D’EÇA JÚNIOR A, et al. Mortalidade por suicídio na população brasileira, 1996-2015: qual é a tendência predominante?. Cadernos Saúde Coletiva, 2019; 27(1): 20-24.

8. MINISTÉRIO DA MULHER, DA FAMÍLIA E DOS DIREITOS HUMANOS (MDH). O Suicídio e automutilação tratados sob a perspectiva da família e do sentido da vida. 2019. Disponível em: 20190104-Manual-de-estudos-dePrevenção-do-Suicidio-MDHMC.pdf. Acessado em: 22 de seeteembro de 2021.

9. MENEZES JG, et al. Enfermagem frente ao suicídio infanto-juvenil. Revista Eletrônica Acervo Saúde, 2021; 13(2): 5925-5925.

10. PEREIRA AS, et al. Fatores de risco e proteção para tentativa de suicídio na adultez emergente. Ciência \& Saúde Coletiva, 2018; 23: 3767-3777.

11. RIBEIRO JM, MOREIRA MR. Uma abordagem sobre o suicídio de adolescentes e jovens no Brasil. Ciência \& Saúde Coletiva, 2018; 23: 2821-2834.

12. RIBEIRO NM, et al. Análise da tendência temporal do suicídio e de sistemas de informações em saúde em relação às tentativas de suicídio. Texto contexto - enferm, 2018; 27(2): e2110016.

13. SILVA DL, et al. Juventude indígena e suicídio: diálogos transdisciplinares, campos de possibilidades e superação de vulnerabilidades. Revista Psicologia Política, 2019; 19(46): 556-569, 2019.

14. SOUSA LMM, et al. A metodologia de revisão integrativa da literatura em enfermagem. Revista Investigação em Enfermagem; 2017; 17: 17-26.

15. SOUZA MLP, ONETY JÚNIOR RTS. Caracterização da mortalidade por suicídio entre indígenas e não indígenas em Roraima, Brasil, 2009-2013. Epidemiologia e Serviços de Saúde, 2017; 26: 887-893.

16. SOUZA MLP. Mortalidade por suicídio entre crianças indígenas no Brasil. Cad. Saúde Pública, 2019; 35(3): e00019219.

17. SOUZA MLP. Narrativas indígenas sobre suicídio no Alto Rio Negro, Brasil: tecendo sentidos. Saude soc., 2016; 25(1); 145-159.

18. STALIANO P, et al. Onde e Como se Suicidam os Guarani e Kaiowá em Mato Grosso do Sul: Confinamento, Jejuvy e Tekoha. Psicol. cienc. prof., 2019; 39: e221674.

19. URREGO-MENDOZA ZC, et al. Narrativas sobre la conducta suicida en pueblos indígenas colombianos, 1993 2013. Rev. Fac. Nac. Salud Pública, 2017; 35(3): 400-409.

20. VARGAS-ESPINDOLA A, et al. Conduta suicida nos povos indígenas: uma revisão do estado da arte. rev.fac.med., 2017; 65(1): 129-135. 